CASE STUDY

\title{
At the Threshold: A Case Study of a Partnership Between a Student Organization and an Educational Development Center
}

\author{
*Stephanie Doktor, Music Department, Colorado College, Colorado Springs, CO, USA \\ Dorothe Bach, Center for Teaching Excellence, University of Virginia, Charlottesville, VA, USA \\ Sophia Abbot, Center for Engaged Learning, Elon University, Elon, NC, USA \\ Jacob Hardin, ReinventED Lab, Charlottesville, VA, USA
}

Contact: bach@virginia.edu

\section{ABSTRACT}

While most students-as-partners case studies have focused on partnerships between students and faculty, this case study outlines a collaboration between a student-led organization and an educational development unit at the University of Virginia. We turn the lens inward and consider the challenges involved in enacting an ethos of radical collegiality (Fielding, 1999) in this unique partnership and our work with training student consultants. We describe the evolution of our collaboration, the programming we developed, and what we learned in the process about sharing power and expertise while negotiating the interests of our respective organizations. We describe our discovery of how deeply institutional norms and academic power structures shaped our perceptions, experiences, and habits. And, using the analytical framework of threshold concepts, we explore our rocky navigation of issues of trust, vulnerability, and role confusion as we moved towards a clearer understanding of and appreciation for the limits of our different types of expertise.

\section{KEYWORDS}

co-creation, power structures, trust, student consultants, student partnerships

This case study describes the formation and development of Co-create UVA, a studentfaculty initiative founded by a student-led organization and an educational development unit at the University of Virginia (UVA). The programming developed by Co-create UVA falls into a category of partnerships that Healey, Flint, and Harrington (2014) call "curriculum design and consultancy." It draws on initiatives such as Elon University's Course-Design Teams, Bryn Mawr and Haverford Colleges' Students as Learners and Teachers (SaLT) Program, and Carleton College's Student Observers (Cook-Sather, Bovill, \& Felten, 2014) and engages student expertise in course design, in new faculty orientation, and in other opportunities for faculty to learn from 
students' perspectives. Co-create UVA initiatives encompass a range of practices and pedagogies, but the common thread is a repositioning of the roles of students and staff (CookSather et al., 2014).

Today, Co-create UVA also shares organizational features common to other studentpartnership programs: It is currently supported by a faculty development unit that curates and facilitates student-faculty partnership work. Though examples of partnerships between educational developers and students have become more common (see e.g., Acai, Kirby, \& Shammas, 2016; Marquis et al., 2015; Werder, Thibou, \& Kaufer, 2012), Co-create UVA is unique in the context of U.S. higher education in that the initiative was originally conceived of and created through a partnership between two independent organizations: student-founded and student-led non-profit organization ReinventED and UVA's Center for Teaching Excellence (CTE).

To make sense of our experiences throughout the creation of our initiative, we use the framework of threshold concepts. Threshold concepts, as defined by Meyer and Land (2005, 2006), are "conceptual gateways or 'portals' that lead to a previously inaccessible, and initially perhaps 'troublesome', way of thinking about something" (2005, p. 373). The shift that occurs in the subjectivity of the learner can be experienced as troublesome, but once the threshold is crossed, it is transformative, integrative, and irreversible (Land et al., 2005, p. 373). CookSather identifies student-faculty partnerships as a threshold concept in educational development, as it challenges norms in higher education that delineate faculty and student roles (Cook-Sather, 2012; Marquis et al., 2015). She proposes that, in addition to understanding students as experts, producers, researchers, and change agents, the idea of a radical collegiality (Fielding, 1999) is frequently foreign and troublesome for faculty (CookSather, 2012, p. 187). For Fielding, collegiality, in contrast to the instrumental and individualistic nature of collaboration, is "overridingly communal in form and in substance" (1999, p. 17). He argues for a collegiality between students and teachers that is marked not only by "a radical, manifest equality in which teachers are also learners and learners also teachers, but also an equality which embraces difference as an important source of practical energy and intellectual creativity" (1999, p. 24). Similarly, radical collegiality is also often challenging for educational developers who invite, hire, and train students for partnership with faculty, as we will see in the second part of this case study. The first half of our article, however, explores threshold concepts within the less familiar context of a partnership between an educational development unit and a student organization.

This article is co-authored by one former and one current staff member at UVA's Center for Teaching Excellence (Stephanie Doktor and Dorothe Bach), a leader of ReinventED (Jacob Hardin), and an external consultant (Sophia Abbot). In contrast to the widespread practice in Students as Partners (SaP) scholarship of bringing together different types of expertise by keeping distinct voices intact, we have chosen to write the article in one voice, an approach that is more consistent with our current identities and the places from which we write. We divided the labor in a way that reflects our different professional goals and the rewards systems in which we operate (Mercer-Mapstone, Dvorakova, Groenendijk, \& Matthews, 2017). Jacob drafted the description of ReinventED, Sophia drafted an account of her consulting work with Co-create UVA, and Stephanie and Dorothe drafted the other parts of the article. What 
you are reading now is the product of numerous rounds of revisions by all co-authors, and the story that our article tells is the result of a collaborative process of shared meaning making.

\section{THE INCEPTION OF CO-CREATE UVA}

In 2014, Keaton Wadzinski, then a second-year undergraduate student, approached CTE staff with an offer to collaborate. Keaton had garnered the support to create ReinventED, a nonprofit organization with the aim of designing the future of education from kindergarten through postsecondary in Charlottesville, Virginia. Keaton and a team of three other students, including Jacob, were seeking to partner with the CTE not as individuals but as leaders of ReinventED, an organization with its own distinct goals. The shared identity of the ReinventED team meant the group felt empowered by the work that students participating as individuals in educational development programming often may not feel. Because of the high level of control in decision-making that students had in this collaboration between two independent, selfdetermined entities, the Co-create UVA initiative can be described as a negotiated curriculum, situated at the highest level of Bovill and Bulley's (2011) ladder of student participation and towards the high autonomy and strong connection end of McKinney, Jarvis, Creasey, and Hermann's (2010) continuum of student voices.

Given this organizational structure, we envisioned ourselves as equal partners in the "between and betwixt" space (Little \& Green, 2012) of educational development typically reserved for professional developers with advanced degrees (Barrineau, Schnaas, Engström, \& Härlin, 2016). However, we soon discovered how deeply academic power structures shaped our perceptions, experiences, and habits. To live up to our espoused values and enact an ethic of reciprocity (Cook-Sather \& Felten, 2017) and a radical collegiality, we needed to cross a number of thresholds that required us to challenge our assumptions about each other's expertise, make ourselves vulnerable, and patiently build trust.

\section{UNDERSTANDING EXPERTISE AND PARTNERSHIP}

\section{Threshold 1: Educational developers learn to trust student leadership}

When CTE and ReinventED began to build Co-create UVA, we brainstormed ideas on where to begin. CTE staff were guided by a conventional notion of expertise and invited an outside expert to facilitate a workshop on student-faculty partnerships. It did not occur to CTE staff to ask their ReinventED collaborators about relevant connections or expertise. When the invited presenter canceled two days before the event, the Co-create UVA team faced the decision to either cancel or create a replacement workshop. Keaton proposed we use the Stanford d.school's "design thinking" approach to introduce students and faculty to the process of co-creating (Both, 2016; Sanders \& Stappers, 2008). As a user-oriented process, he argued, this approach would encourage empathy, generate ideas, and enable faculty and students to hear and learn from each other's' unique perspectives. Unfamiliar with the Design Thinking methodology, CTE staff members were confused by the process and skeptical about its ability to achieve the desired outcomes.

Ultimately, through Keaton's skillful pitch, CTE staff were able to challenge their notions of who holds enough expertise and power to facilitate a campus-wide CTE event, and despite their initial hesitation, they became eager to see this experimental approach in action. During 
the preparation, they served as a sounding board, lending their understanding of the faculty perspective to what became a student-driven planning process. Two days later, after welcoming participants to the session, CTE staff sat back and observed how Keaton led groups of faculty and students through the process of interviewing each other with empathy, brainstorming ideas for solutions to identified classroom problems, and pitching them to the larger group. They witnessed how Keaton's facilitation skills matched the ambition of his vision and faculty and student participants left with concrete ideas for co-creating learning experiences together.

This first event was an exercise in experiencing the push and pull involved in role reversal and shifting power dynamics, which required a level of vulnerability and trust on the part of CTE staff as they relinquished control. Building on our initial success, we refined the design thinking model for student-faculty workshops and have offered them multiple times locally and nationally, with ReinventED leaders driving the process and CTE staff in a supporting role.

\section{Threshold 2: Students gain insight into faculty perspectives}

The success of our pilot year inspired us to apply for an internal UVA grant to build a comprehensive program. We wanted to encourage student-faculty collaborations through several mechanisms, including trained undergraduate student consultants, grants for studentfaculty course design teams, design thinking workshops, and informal student-faculty conversations at the orientation for new faculty. During the process of writing the grant, we encountered challenges that were in many ways the inverse of the ones we previously described: ReinventED collaborators struggled to understand the perspectives of faculty and of educational developers.

A conflict arose when the funding agency intervened in the grant writing process and suggested that ReinventED partner with UVA's Student Council on a joint proposal that would combine funding for two different student-led initiatives. Initially, this seemed like an attractive addition to the Co-create UVA portfolio, but it soon became clear that the goals of the Student Council were quite different from those of Co-create UVA. Whereas Co-create UVA aimed to cultivate student-faculty partnerships to enhance teaching and learning, the Student Council initiative focused on educating UVA faculty about the student-run academic conduct system. To all of us, the idea seemed to stretch the current mission of Co-create UVA and we agreed that we needed to consider our options carefully. Furthermore, CTE staff believed that the Student Council proposal communicated a coercive approach to "training" faculty and was written in a condescending tone. CTE staff believed the Student Council sought to reverse the power dynamics between students and faculty and have students educate faculty, and this was antithetical to the aims of Co-Create UVA's proposal, which sought to level pre-existing power hierarchies and foster reciprocal relationships.

Because of those risks, CTE staff made clear to ReinventED leaders that CTE as an organization could not associate itself with the Student Council proposal. While some ReinventED leaders agreed with CTE staff's perspective that the Student Council's approach was problematic, others were concerned Co-create UVA would not receive funding without Student Council co-authorship. ReinventED leaders hoped they could work with the Student Council to help them adopt a more collaborative approach to working with faculty. 
Although CTE staff communicated that they could not continue the collaboration if ReinventED leaders decided to partner with the Student Council, they tried hard not to enact conventional power dynamics and refrained from telling their partners what to do. However, this refusal to take leadership and drive decision-making for the sake of preserving the ideal of equal power caused unnecessary debate between ReinventED leaders who disagreed with each other about the merger.

Over the course of our heated conversations, ReinventED leaders began to more clearly understand the professional goals and priorities of their CTE partners. Considering the CTE's experience with this particular grant agency, ReinventED leaders also decided to trust CTE staff's reasoning that a well-formulated argument for separating the proposals might be more persuasive to the grant agency than stitching together poorly aligned initiatives. Once it became clear that CTE partners strongly believed in the future of our proposal on its own, confidence grew among the ReinventED leaders as well.

In working through this conflict, we all felt uncertain whether this would mean the end of our partnership. As we look back at this moment, we agree that what kept us together was our willingness to carefully hear each other out, to be open to changing our views in light of new evidence, and to accept the limits of our expertise. By paying attention to the process, we discovered the depth of our commitment to a partnership based on mutual respect (National Union of Students, 2012). Moving forward, a radical commitment to embrace difference "as an important source of practical energy and intellectual creativity" (Fielding, 1999) became a core piece of our philosophy. It influenced not only ReinventED's work with the CTE, but also its overall ethos for partnering with other organizations and individuals.

In the end, Co-create UVA and the Student Council received separate grants, allowing them to pursue their projects independently. With funding successfully secured, Co-create UVA set out to inspire "collective creativity" (Sanders \& Stappers, 2008, p. 6) in students and faculty through an interlocking set of initiatives.

\section{Threshold 3: Educational developers learn to trust the value of student experience and perspectives}

We now shift our focus away from the partnership between CTE staff and ReinventED leaders and towards the experiences of CTE staff in training UVA students for their roles as teaching consultants. Systematically embedding students' perspectives into CTE programming had been a goal from Co-create UVA's inception. CTE's week-long Course Design Institute (CDI) seemed like the ideal place to begin. Established in 2008, CDI today helps approximately 100 instructors per year design learning-focused courses. Considering issues of student motivation throughout CDI, participants repeatedly find themselves speculating about how students may respond to their syllabi and assignment descriptions. With rough drafts being workshopped by faculty peers on days three and four of the Institute, it seemed logical to offer opportunities to consult with students as well.

In 2014, prior to the existence of Co-create UVA, CTE staff had assumed that, in order for undergraduate students to be successful when sharing their perspectives in the context of a one-time, short consultation session, they needed a basic understanding of learning-focused design principles. Accordingly, the initial training designed by CTE staff heavily emphasized 
pedagogical knowledge, stemming from the CTE staff's limited understanding of what constitutes expertise. In the day-long training, they inducted eight student consultants into the ins and outs of backward design principles, Fink's taxonomy, alignment, and the analysis of sample syllabi with the help of a syllabus rubric (Palmer, Bach, \& Streifer, 2014). Although trust in student expertise was an espoused value, the training program belied the CTE staff's fear that students' experiences as learners would be insufficient for providing valuable contributions. Thus, instead of valuing students' tacit knowledge, CTE staff attempted to equip students with knowledge in a field in which students were not experts. In feedback following the CDI consulting experience, students reported role confusion and a sense of overwhelm.

To restructure the training, CTE staff and ReinventED leaders consulted with Sophia Abbot, a former student consultant in Bryn Mawr's SaLT program who was at that time working as an educational developer at Trinity University. In the design and facilitation of 2015 training, Sophia emphasized students' ability to consult on the basis of their expertise as learners and their preexisting understanding of what helped them be successful. Sophia encouraged CTE staff to trust that by advising students to frame feedback around what supports their learning, student feedback would remain genuine and useful. In cases where students were confused by or misinterpreted a course document such as an assignment description, their confusion could serve as a point of learning for the faculty around where they needed to communicate more transparently.

Sophia's student consultant training primarily consisted of exercises in deep listening, practice in narrating thoughts out loud while reading syllabi and assignment descriptions, and affirmative feedback that clearly communicated the value of students' perspectives. Students also reflected on the limitations of their perspectives; they noted that theirs only constituted one of many possible views, and that they were not and didn't need to be pedagogical experts. To further help them understand their roles in relationship to pedagogical experts and to build empathy with instructors (Cook-Sather, 2015; Cook-Sather \& Mejia, 2018), the undergraduate consultants attended the first day of the CDI, where they learned about theories of student motivation and observed instructors interact with CTE faculty. During the debriefing following this observation, students shared how surprised they were by concepts they had never thought about, how difficult teaching seemed to be, and how much instructors seem to care. They also realized that teaching and learning looked different in different disciplines and that they could not generalize from their experience.

Overall, in their feedback on the restructured training, students reported that they felt confident and empowered in a way that the initial trainees did not. Knowing the strengths inherent in their perspectives as students and the limits of their expertise, they were confident about their ability to offer valuable insights by simply narrating their thoughts while reading course documents and responding to instructor questions more broadly.

\section{At the Threshold: Co-create UVA Today}

Today, Co-create UVA offers a variety of opportunities for dialogue between students and instructors. For example, our student-faculty luncheon at UVA's orientation for new faculty aims at shifting instructors' perceptions of students as lacking in expertise to seeing them as important resources and potential collaborators for designing, assessing, and enhancing 
teaching and learning (Cook-Sather, 2016). Instructors participating in the CTE's week-long Course Design Institute receive feedback from undergraduate student consultants on drafts of their syllabi and assignments. Fully integrated into the CTE's consultation program, these students also conduct mid-semester focus groups and in-class observations for instructors interested in undergraduate student perspectives. Finally, Co-create UVA grants support students and faculty who wish to design courses together.

There are a number of challenges to maintaining and developing our initiatives. After the initial funds expired, we had to find ways to leverage existing CTE structures and resources. Recruitment of students has become more difficult after ReinventED leaders graduated. With the loss of the collaborating student organization, the Center no longer has an independent partner to provide sustained and empowered student input. Design Thinking workshops have been suspended, and student-faculty co-design grants have become part of a broader teaching enhancement grants program. With CTE staff now overseeing the student consultants as part of its overall consultant program - which includes faculty, graduate students, and undergraduate students - there is less of a team spirit among undergraduate consultants and therefore a lack of identity and ownership. Without student leadership, Co-create UVA relies solely on CTE's efforts and has become absorbed into CTE operations.

\section{CONCLUSIONS}

Although there is ample research on the challenges inherent in partnership work, few case studies have explored the experience of educational developers and student leaders seeking to create a faculty-student partnership initiative in collaboration from the ground up. While the partnership presented in this article was in many ways unique, the lessons we learned are applicable to other contexts. Our challenges with bringing multiple voices into dialogue in a well-worn hierarchal system reflect those previously reported (Mihans, Richard, Long, \& Felten, 2008; Murphy, Nixon, Brooman, \& Fearon, 2017). In our commitment to flatten power structures, we have walked the path of others who found themselves in the throes of unproductive modes of role confusion and leadership challenges (Mercer-Mapstone et al., 2017).

Our experiences also suggest that collaborations between educational developers and student leaders are subject to pressures similar to those experienced in collaborations between faculty and students. Educational development and student organizations may both be situated in the liminal space between students and faculty, but preexisting power hierarchies reach into this space, creating barriers and thresholds that need to be crossed. Student leaders and educational developers who engage in partnership should monitor their actions and reactions in these collaborations, as they often speak louder than their stated goals and espoused values. They should also expect role confusion, uncertainty about what constitutes expertise, and a fear of giving up control as part of the process. Overzealous efforts to flatten power structures can further lead to leadership challenges and protracted decision-making. However, our experience confirms that collaborations between Centers and student leaders hold the potential to enrich educational development efforts and strengthen student agency. 


\section{NOTE ON CONTRIBUTORS}

Stephanie Doktor is a Visiting Assistant Professor of Music at Colorado College, United States, and an avid jazz fan.

Dorothe Bach is associate director and professor, general faculty, at the Center for Teaching Excellence, University of Virginia, United States.

Jacob Hardin is the former program director for ReinventED and soon to be Masters student at the NYU Steinhardt Teacher Residency Program, United States.

Sophia Abbot is the Graduate Apprentice for the Center for Engaged Learning and a graduate student in Elon's Masters of Higher Education, United States.

\section{REFERENCES}

Acai, A., Kirby, S., \& Shammas, R. (2016). Reflections on an international "Change Institute" for students as partners: A student perspective. International Journal for Students as Partners, 1(1). https://doi.org/10.15173/ijsap.v1i1.3084ht

Barrineau, S., Schnaas, U., Engström, A., \& Härlin, F. (2016). Breaking ground and building bridges: A critical reflection on student-faculty partnerships in academic development. International Journal for Academic Development, 21(1), 79-83. https://doi.org/10.1080/1360144X.2015.1120735

Bovill, C., \& Bulley, C. J. (2011). A model of active student participation in curriculum design: Exploring desirability and possibility. In C. Rust (Ed.), Improving student learning 18: Global theories and local practices - Institutional, disciplinary, and cultural variations (pp. 176-188).Oxford, UK: Oxford Brookes University. Retrieved from http://eprints.gla.ac.uk/57709.

Both, T. (2016). A D. School Design Project Guide. Hasso Plattner Institute of Design at Stanford. Retrieved from https://dschool.stanford.edu/resources/design-project-guide-1

Cook-Sather, A. (2012). Student-faculty partnership in explorations of pedagogical practice: A threshold concept in academic development. International Journal for Academic Development, 19(3), 186-198. https://doi.org/10.1080/1360144X.2013.805694

Cook-Sather, A. (2015). Dialogue across differences of position, perspective, and identity: Reflective practice in/on student-faculty pedagogical partnership program. Teachers College Record, 117(2), 1-29. Retrieved from http://repository.brynmawr.edu/edu pubs/32

Cook-Sather, A. (2016). Undergraduate students as partners in new faculty orientation and academic development. International Journal for Academic Development, 21(2), 151-162. https://doi.org/10.1080/1360144X2016.1156543

Cook-Sather, A., Bovill, C., \& Felten, P. (2014). Engaging students as partners in learning and teaching: A guide for faculty. San Francisco, CA: Jossey-Bass. 
Cook-Sather, A., \& Felten, P. (2017). Ethics of academic leadership: Guiding learning and teaching. In F. Su \& M. Wood (Eds.), Cosmopolitan perspectives on academic leadership in higher education (pp. 175-191). New York, NY: Bloomsbury Academic.

Cook-Sather, A., \& Mejia, Y. (2018, July 20). Students experience empowerment and empathy through pedagogical partnership [Web log post]. Retrieved from https://www.bera.ac.uk/blog/students-experience-empowerment-and-empathy-throughpedagogical-partnership

Fielding, M. (1999). Radical collegiality: Affirming teaching as an inclusive professional practice. Australian Educational Researcher, 26, 2, 1-34. https://doi.org/10.1007/BF03219692

Healey, M., Flint, A., \& Harrington, K. (2014). Developing students as partners in learning and teaching in higher education. York: HE Academy. Retrieved from https://www.heacademy.ac.uk/knowledge-hub/engagement-through-partnershipstudents-partners-learning-and-teaching-higher

Little, D., \& Green, D. A. (2012). Betwixt and between: Academic developers in the margins. International Journal for Academic Development, 17(3), 203-215.

https://doi.org/10.1080/1360144X.2012.700895

Marquis, E., Puri, V., Wan, S., Ahmad, A., Goff, L., Knorr, K., Vassileva, I., \& Woo, J. (2015). Navigating the threshold of student-staff partnerships: A case study from an Ontario teaching and learning institute. International Journal for Academic Development, 21(1), 415. https://doi.org/10.1080/1360144X.2015.113538

McKinney, K., Jarvis, P., Creasey, G., \& Hermann, D. (2010). A range of student voices in the scholarship of teaching and learning. In C. Werder \& M. M. Otis (Eds.), Engaging student voices in the study of teaching and learning (pp. 81-95). Sterling, VA: Stylus.

Meyer, J. H., \& Land, R. (2005). Threshold concepts and troublesome knowledge (2): Epistemological considerations and a conceptual framework for teaching and learning. Higher Education, 49(3), 373-388. https://doi.org/10.1007/s10734-004-6779-5

Meyer, J. H., \& Land, R. (2006). Overcoming barriers to student understanding: Threshold concepts and troublesome knowledge. New York, NY: Routledge.

Mercer-Mapstone, L., Dvorakova, L. S., Groenendijk, L., \& Matthews, K. (2017). Idealism, conflict, leadership, and labels: Reflections on co-facilitation as partnership practice. Teaching and Learning Together in Higher Education, 1(21), 1-9. Retrieved from https://repository.brynmawr.edu/tlthe/vol1/iss21/8

Mihans, I. I., Richard, J., Long, D. T., \& Felten, P. (2008). Power and expertise: Student-faculty collaboration in course design and the scholarship of teaching and learning. International Journal for the Scholarship of Teaching and Learning, 2(2), 1-8. https://doi.org/10.20429/ijsotl.2008.020216

Murphy, R., Nixon, S., Brooman, S., \& Fearon, D. (2017). “I am wary of giving too much power to students": Addressing the "but" in the principle of staff-student partnership. International Journal of Students as Partners, 1(1), 1-16. https://doi.org/10.15173/ijsap.v1i1.3055

National Union of Students (2012). A manifesto for partnership. London: National Union of Students. Retrieved from https://www.nusconnect.org.uk/resources/a-manifesto-forpartnership 
Palmer, M. S., Bach, D. J., \& Streifer, A. C. (2014). Measuring the promise: A learning-focused syllabus rubric. To Improve the Academy: A Journal of Educational Development, 33(1), 14-36. https://doi.org/10.1002/tia2.20004

Sanders, E. B. N., \& Stappers, P. J. (2008). Co-creation and the new landscapes of design. Codesign, 4(1), 5-18. https://doi.org/10.1080/15710880701875068

Werder, C., Thibou, S., \& Kaufer, B. (2012). Students as co-inquirers: A requisite threshold concept in educational development? Journal of Faculty Development, 26(3), 34-38. 